\title{
Al-Li Alloy 1441 for Fuselage Applications
}

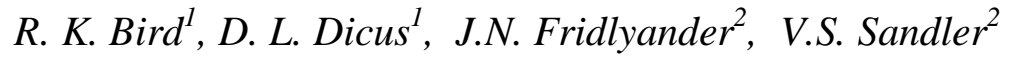 \\ ${ }^{1}$ National Aeronautics and Space Administration (NASA) Langley Research Center, Hampton, \\ Virginia, USA \\ ${ }^{2}$ All-Russia Institute of Aviation Materials (VIAM), Moscow, Russia
}

Key Words: aluminum-lithium, fuselage pressurization fatigue, tensile properties, toughness, fatigue life, fatigue crack growth

\begin{abstract}
A cooperative investigation was conducted to evaluate $\mathrm{Al}-\mathrm{Cu}-\mathrm{Mg}-\mathrm{Li}$ alloy 1441 for long service life fuselage applications. Alloy 1441 is currently being used for fuselage applications on the Russian Be-103 amphibious aircraft, and is expected to be used for fuselage skin on a new Tupolev business class aircraft. Alloy 1441 is cold-rollable and has several attributes that make it attractive for fuselage skin applications. These attributes include lower density and higher specific modulus with similar strength as compared to conventional $\mathrm{Al}-\mathrm{Cu}-\mathrm{Mg}$ alloys.

Cold-rolled 1441 Al-Li sheet specimens were tested at NASA Langley Research Center (LaRC) and at the All-Russia Institute of Aviation Materials (VIAM) in Russia to evaluate tensile properties, fracture toughness, impact resistance, fatigue life and fatigue crack growth rate. In addition, fuselage panels were fabricated by Tupolev Design Bureau (TDB) using 1441 skins and $\mathrm{Al}-\mathrm{Zn}-\mathrm{Mg}-\mathrm{Cu}$ alloy stiffeners. The panels were subjected to cyclic pressurization fatigue tests at TDB and at LaRC to simulate fuselage pressurization/depressurization during aircraft service. This paper discusses the results from this investigation.
\end{abstract}

\section{Introduction}

The low density and good mechanical properties of Al-Li alloys make them attractive for many structural applications, especially in the aerospace industry [1]. Research and development efforts in Russia and the United States have focused on advanced Al-Li alloys for aerospace applications where reduced structural weight is a critical goal [2,3]. The All-Russia Institute of Aviation Materials (VIAM) has developed a new Al-Li alloy series with attractive characteristics. These characteristics include moderate to high strength, good weldability, good elevated temperature and cryogenic mechanical properties, high corrosion resistance, and superplastic formability [4]. This new alloy series includes Al-Cu-Li alloys (1450, 1460), Al-Mg-Li alloys (1420, 1424), and Al-Cu-Mg-Li alloys (1440, 1441). Various extruded and forged semiproducts, plates, and hot-rolled sheets of these alloys are produced on an industrial basis.

Alloy 1441 has the potential to substitute for D16 Al or $1163 \mathrm{Al}$ on aircraft fuselage structures. (D16 Al and $1163 \mathrm{Al}$ are Russian analogs of $2024 \mathrm{Al}$ and $2524 \mathrm{Al}$, respectively.) Compared to these Al-Cu-Mg alloys, $1441 \mathrm{Al}-\mathrm{Li}$ alloy has similar strength but exhibits $7 \%$ lower density and $12 \%$ higher modulus, as well as other improved properties [4]. In addition, VIAM and Kamensk-Uralsky Metallurgical Plant (KUMZ) have optimized the cold rolling process to produce coils of 1441 alloy sheet as thin as $0.5 \mathrm{~mm}$ [4]. Since 1994, NASA Langley Research Center has engaged in cooperative research activities with VIAM and the All-Russia Institute of Light Alloys (VILS) in Moscow, Russia, to evaluate 1441 Al-Li alloy for fuselage skin applications. The work included cold rolling and heat treatment process development, characterization of microstructure 
and mechanical properties of cold-rolled sheet, and evaluation of durability of fuselage panels fabricated with 1441 Al-Li skin. This paper focuses on the mechanical properties of cold rolled sheet and the durability of the fuselage panels.

\section{Materials}

The 1441 Al-Li material evaluated under this cooperative activity was provided by VIAM. The nominal composition of the alloy, in weight percent, was $\mathrm{Al}-1.6 \mathrm{Cu}-1.7 \mathrm{Li}-0.95 \mathrm{Mg}-0.08$ $\mathrm{Zr}$. The alloy was evaluated as cold-rolled sheet in two different tempers. The two tempers were $\mathrm{T} 1$ condition (solution treated at $530^{\circ} \mathrm{C}$, water quenched, stretched, aged at $150^{\circ} \mathrm{C}$ for 24 hours) and $\mathrm{T} 11$ condition (solution treated at $530^{\circ} \mathrm{C}$, water quenched, stretched, aged at $150^{\circ} \mathrm{C}$ for 4 hours followed by $24-30$ hours at $170^{\circ} \mathrm{C}$ ). For comparative purposes, cold-rolled $1163 \mathrm{Al}$ alloy sheet was also evaluated.

\section{Mechanical Properties of Cold-Rolled Sheet}

\section{Tensile results}

Table 1 shows the tensile properties, measured at VIAM, of 1441 Al-Li alloy sheet in the $\mathrm{T} 1$ and T11 conditions. A more detailed discussion of tensile properties and heat treatment effects can be found in Reference 4. Moderate strength and high elongation were associated with the T1 temper. The T11 temper resulted in increased strength but decreased elongation. These data show a modest level of anisotropy which is less than that commonly associated with Al-Li alloys.

Table 1: $\quad$ Tensile properties of 1441 Al-Li sheet [4].

\begin{tabular}{|c|c|ccc|}
\hline Orientation & Temper & $\begin{array}{c}\text { Tensile } \\
\text { Strength } \\
\text { (MPa) }\end{array}$ & $\begin{array}{c}\text { Yield } \\
\text { Strength, } \\
\text { (MPa) }\end{array}$ & $\begin{array}{c}\text { Plastic } \\
\text { Elongation, } \\
\text { (\%) }\end{array}$ \\
\hline Longitudinal & $\mathrm{T} 1$ & 415 & 315 & 16.0 \\
& $\mathrm{~T} 11$ & 450 & 395 & 9.5 \\
\hline Transverse & $\mathrm{T} 1$ & 430 & 315 & 14.0 \\
& $\mathrm{~T} 11$ & 455 & 390 & 9.0 \\
\hline $\mathbf{4 5}^{\circ}$ & $\mathrm{T} 1$ & 405 & 280 & 18.0 \\
& $\mathrm{~T} 11$ & 440 & 380 & 8.5 \\
\hline
\end{tabular}

\section{Fracture toughness results}

Table 2 shows the fracture toughness, measured at VIAM, of 1441 Al-Li alloy sheet in the $\mathrm{T} 1$ and T11 conditions. Sheet thickness ranged from $1.4 \mathrm{~mm}$ to $1.8 \mathrm{~mm}$. The center-crack tension fracture toughness specimens had widths in the range of $200 \mathrm{~mm}$ to $600 \mathrm{~mm}$ with initial cracklength-to-width ratio in the range of $0.3-0.4$. Doubling the specimen width resulted in a $25 \%$ increase in fracture toughness. Both tempers exhibited similar toughness levels and only minor toughness anisotropy. The toughness of $1441 \mathrm{Al}-\mathrm{Li}$ sheet was similar to that of 2-4 mm thick 1163-AT Al alloy sheet, which exhibited a toughness of approximately $100 \mathrm{MPa}-\mathrm{m}^{1 / 2}$ for $400 \mathrm{~mm}$ wide sheet in the LT orientation.

Although the T1 and T11 tempers exhibited similar toughness levels, the impact resistance was sensitive to temper. Table 3 shows the impact resistance measured at VIAM for $8 \mathrm{~mm}$ thick 1441 Al-Li sheet. The T11 temper showed a significantly diminished impact energy (34\% to $45 \%$ lower) as compared to the $\mathrm{T} 1$ temper.

\section{Fatigue crack growth rate results}

Table 4 shows the fatigue crack growth rate $(\mathrm{d} 2 \mathrm{a} / \mathrm{dN})$, measured at VIAM, of $1441 \mathrm{Al}-\mathrm{Li}$ alloy sheet in the T1 and T11 conditions. Sheet thickness ranged from $1.2 \mathrm{~mm}$ to $2.0 \mathrm{~mm}$ and the 
center-crack tension specimen width ranged from $300 \mathrm{~mm}$ to $400 \mathrm{~mm}$. For comparative purposes, data for $1163 \mathrm{Al}$ alloy in the T3 condition are also shown. Tests were performed at a maximum fatigue stress of $100 \mathrm{MPa}$ and a frequency of $5 \mathrm{~Hz}$. The ratio of minimum fatigue stress to maximum fatigue stress (R) was 0 . Alloy 1441 in the T1 temper exhibited significantly better fatigue resistance than either 1441-T11 or 1163-T3. Fatigue crack growth rates for the 1441-T11 were similar to those for 1163-T3.

Table 2: $\quad$ Fracture toughness $\left(K_{C}\right)$ of 1441 Al-Li sheet $(1.4 \mathrm{~mm}-1.8 \mathrm{~mm}$ thick) and 1163 Al sheet (2mm - 4mm thick) [4].

\begin{tabular}{|c|c|c|c|c|}
\hline \multirow{2}{*}{ Alloy } & Width & \multirow{2}{*}{ Temper } & \multicolumn{2}{|c|}{$\mathbf{K}_{\mathbf{C}},\left(\mathbf{M P a}-\mathbf{m}^{\mathbf{1} \mathbf{2}}\right)$} \\
\cline { 4 - 5 } & $(\mathbf{m m})$ & & $\mathbf{L T}$ & $\mathbf{T L}$ \\
\hline \multirow{4}{*}{$\mathbf{1 4 4 1}$} & 200 & $\mathrm{~T} 1$ & 76.5 & 73.0 \\
& & $\mathrm{~T} 11$ & 76.6 & 76.8 \\
\cline { 2 - 5 } & 400 & $\mathrm{~T} 1$ & 99.2 & 98.5 \\
& & $\mathrm{~T} 11$ & 99.8 & 102.0 \\
\cline { 2 - 5 } & 600 & $\mathrm{~T} 1$ & 124 & ---- \\
& & $\mathrm{T} 11$ & ---- & ---- \\
\hline
\end{tabular}

Table 3: $\quad$ Impact energy of 8-mm thick 1441 Al-Li sheet [4].

\begin{tabular}{|c|c|c|}
\hline \multirow{2}{*}{ Temper } & \multicolumn{2}{|c|}{ Impact energy, $\left(\mathbf{J} / \mathbf{c m}^{2}\right)$} \\
\cline { 2 - 3 } & Longitudinal & Transverse \\
\hline T1 & 19.2 & 17.8 \\
T11 & 12.6 & 9.8 \\
\hline
\end{tabular}

Table 4: $\quad$ Fatigue crack growth rate (d2a/dN) of $1441 \mathrm{Al}-\mathrm{Li}$ and $1163 \mathrm{Al}$ sheet [4].

\begin{tabular}{|c|c|c|c|c|}
\hline \multirow[t]{2}{*}{ Alloy/Temper } & \multirow[t]{2}{*}{ Orientation } & \multirow{2}{*}{$\begin{array}{c}\Delta K, \\
\left(\mathrm{MPa}^{\mathrm{M}} \mathrm{m}^{1 / 2}\right)\end{array}$} & \multicolumn{2}{|c|}{$\mathrm{d}(2 \mathrm{a}) / \mathrm{dN},(\mu \mathrm{m} / \mathrm{cycle})$} \\
\hline & & & average & range \\
\hline \multirow{4}{*}{ 1441-T1 } & \multirow[b]{2}{*}{ LT } & 18.6 & 0.37 & $0.28-0.40$ \\
\hline & & 31.0 & 2.00 & $1.26-3.17$ \\
\hline & \multirow[b]{2}{*}{$\mathrm{TL}$} & 18.6 & 0.29 & $0.14-0.51$ \\
\hline & & 31.0 & 1.50 & $0.69-2.57$ \\
\hline \multirow{4}{*}{ 1441-T11 } & \multirow[b]{2}{*}{$\mathrm{LT}$} & 18.6 & 0.79 & $0.42-1.21$ \\
\hline & & 31.0 & 7.30 & $3.75-13.0$ \\
\hline & \multirow[b]{2}{*}{ TL } & 18.6 & 0.70 & $0.68-0.73$ \\
\hline & & 31.0 & 3.40 & $2.56-4.14$ \\
\hline \multirow{4}{*}{ 1163-T3 } & \multirow[b]{2}{*}{ LT } & 18.6 & 0.78 & $0.62-0.98$ \\
\hline & & 31.0 & 3.85 & $3.30-4.40$ \\
\hline & \multirow[b]{2}{*}{$\mathrm{TL}$} & 18.6 & 0.92 & $0.74-1.14$ \\
\hline & & 31.0 & 4.70 & $3.44-5.53$ \\
\hline
\end{tabular}

Fatigue results

The S-N fatigue behavior of smooth and notched 1441-T1 Al-Li sheet specimens tested at LaRC is shown in figure 1. Also shown are reference data from VIAM for $1163 \mathrm{Al}$ alloy plate. 
The data for the smooth $1441 \mathrm{Al}-\mathrm{Li}$ specimens indicated a fatigue run-out at 1,000,000 cycles at approximately $170 \mathrm{MPa}$. This run-out was higher than the endurance limit for $1163 \mathrm{Al}$, which was reported to be approximately $120 \mathrm{MPa}$ at 2,000,000 cycles. The fatigue data for notched specimens showed a significantly higher fatigue strength and life for 1441 Al-Li compared to $1163 \mathrm{Al}$.

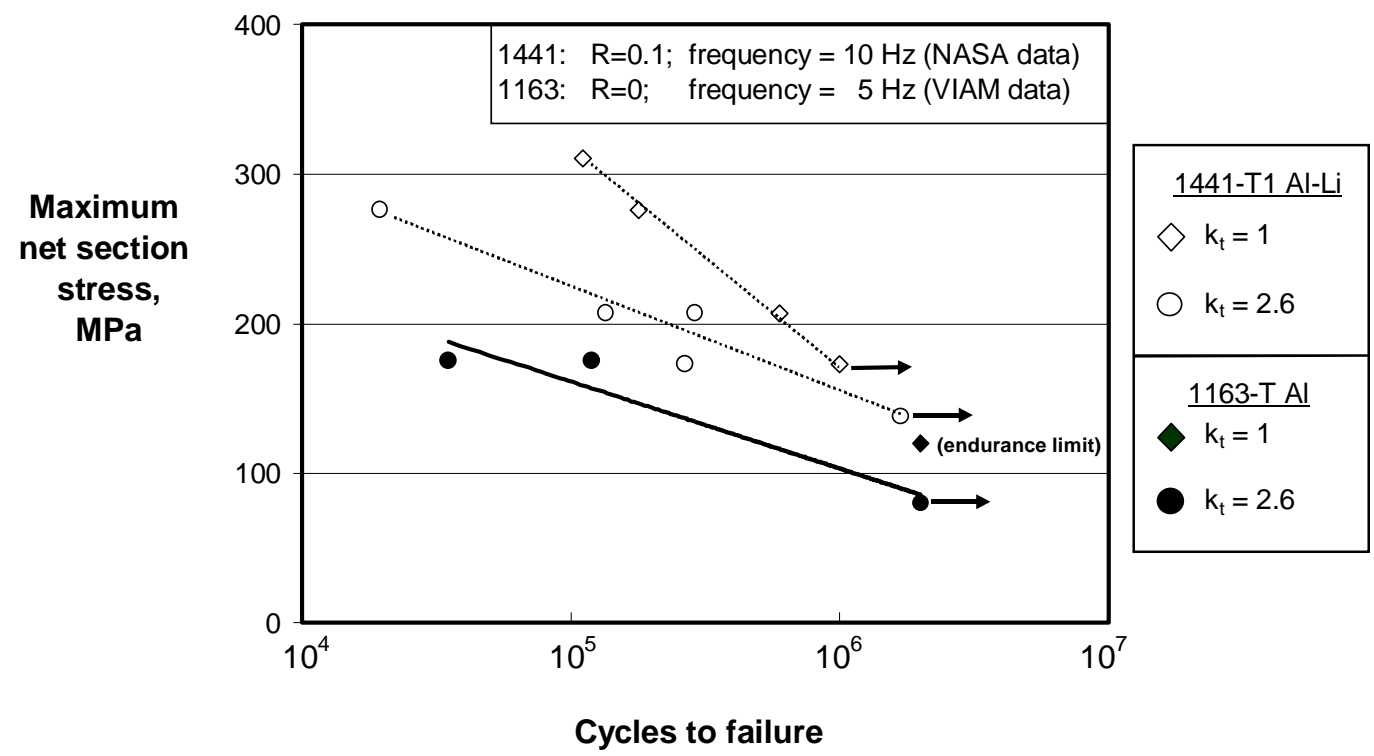

Figure 1: Fatigue behavior of 1441-T1 Al-Li sheet and 1163-T Al plate (long. orient.) [5].

\section{Fuselage Panel Pressurization Fatigue Tests}

A detailed description of the fuselage panels, test fixtures and techniques, and test results is available in Reference 5. A brief description of the panel tests follows. Figure 2 shows a photograph of one of the fuselage panels. The panels were singly-curved and were fabricated by Tupolev Design Bureau (TDB) using the Tupolev-204 fuselage design, having dimensions of approximately $1.5 \mathrm{~m}$ in length and $1.5 \mathrm{~m}$ in width with a radius of curvature of $1.9 \mathrm{~m}$. Each panel contained two riveted longitudinal single skin overlap joints with different rivet spacings. Nine longitudinal blade stiffeners fabricated from V95pchT2 Al (analog to $7475 \mathrm{Al}$ ) alloy were riveted to each panel. In addition, three ring frames fabricated from $1441 \mathrm{Al}-\mathrm{Li}$ alloy were riveted to the panel circumference.

Two panels were tested in Russia at TDB and two were tested at LaRC. In both cases, the panels were mounted in back-to-back fashion in a pressurization fixture and tested simultaneously to a peak pressure of $65 \mathrm{kPa}$ at a rate of approximately 3 cycles per minute. This peak pressure corresponded to a maximum hoop stress of $70 \mathrm{MPa}$. The test fixture used at Tupolev employed hinges for panel attachment on the straight edges and flexible seals that allowed the curved edges of the panel to deflect, whereas the panels tested at LaRC were constrained along all four edges. The pressurization tests were interrupted periodically to visually examine the riveted joints in each panel for fatigue cracking.

The results of the panel pressurization fatigue tests are shown in figure 3. Shown for comparison are results provided by VIAM from a Tu-204 fuselage panel constructed using conventional $1163 \mathrm{Al}$ skin and tested at TDB. The conventional panel failed after 163,000 pressurization cycles. Both 1441 Al-Li panels tested at TDB accumulated 250,000 cycles without failure and without initiation of fatigue cracks. However, one of the panels tested at LaRC failed 
catastrophically along one of the riveted splice joints after 193,000 pressurization cycles.

Fractographic analysis revealed that fatigue cracks initiated and propagated in the $1441 \mathrm{Al}-\mathrm{Li}$ skin on the interior side of the overlap joint along a rivet line. Thus, these cracks were not observed until fracture occurred. The other panel tested at LaRC remained intact, but examination revealed the existence of small fatigue cracks, less than one inch in length, in the riveted joints. The difference in pressurization fatigue life of the 1441 Al-Li panels tested at LaRC and Tupolev was attributed to the different stress states developed as a result of the different panel constraints. In all cases, however, the panels with 1441 Al-Li skin had a longer pressurization fatigue life than did panels with conventional $1163 \mathrm{Al}$ alloy skin.

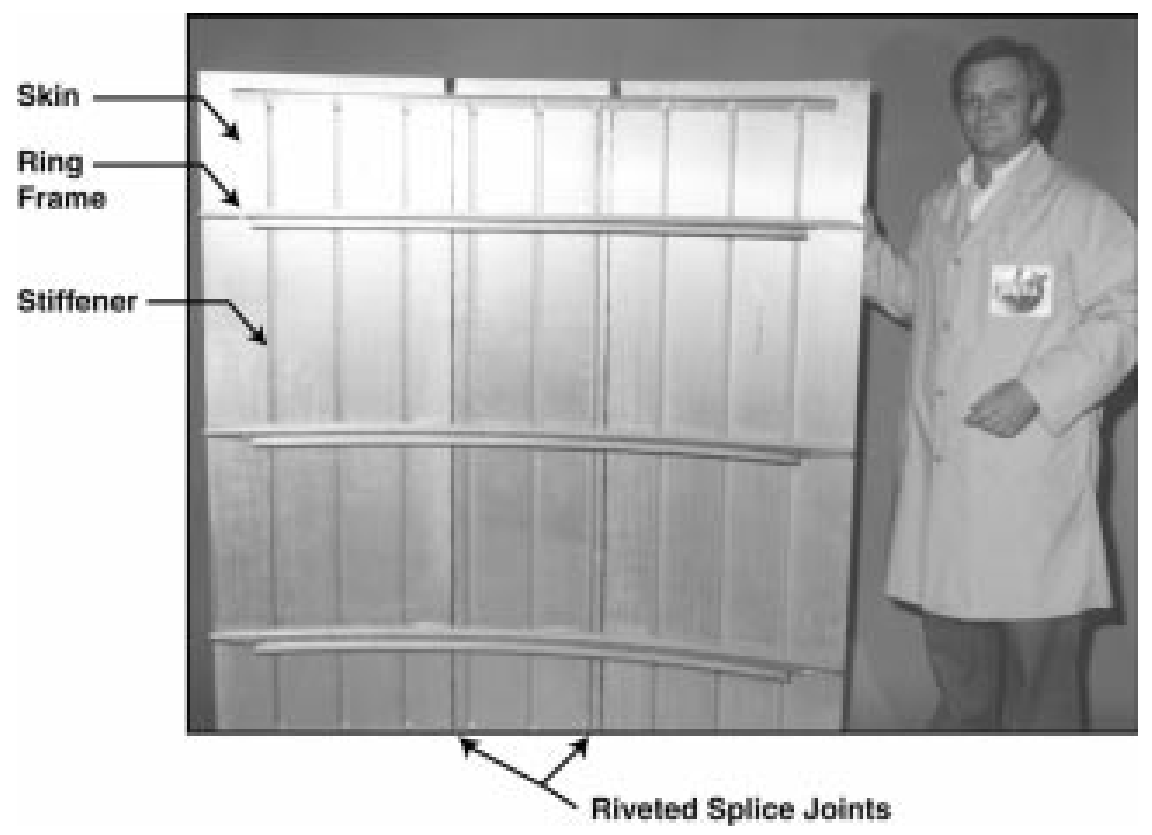

Figure 2: $\quad$ Fuselage panel with 1441 Al-Li skin.

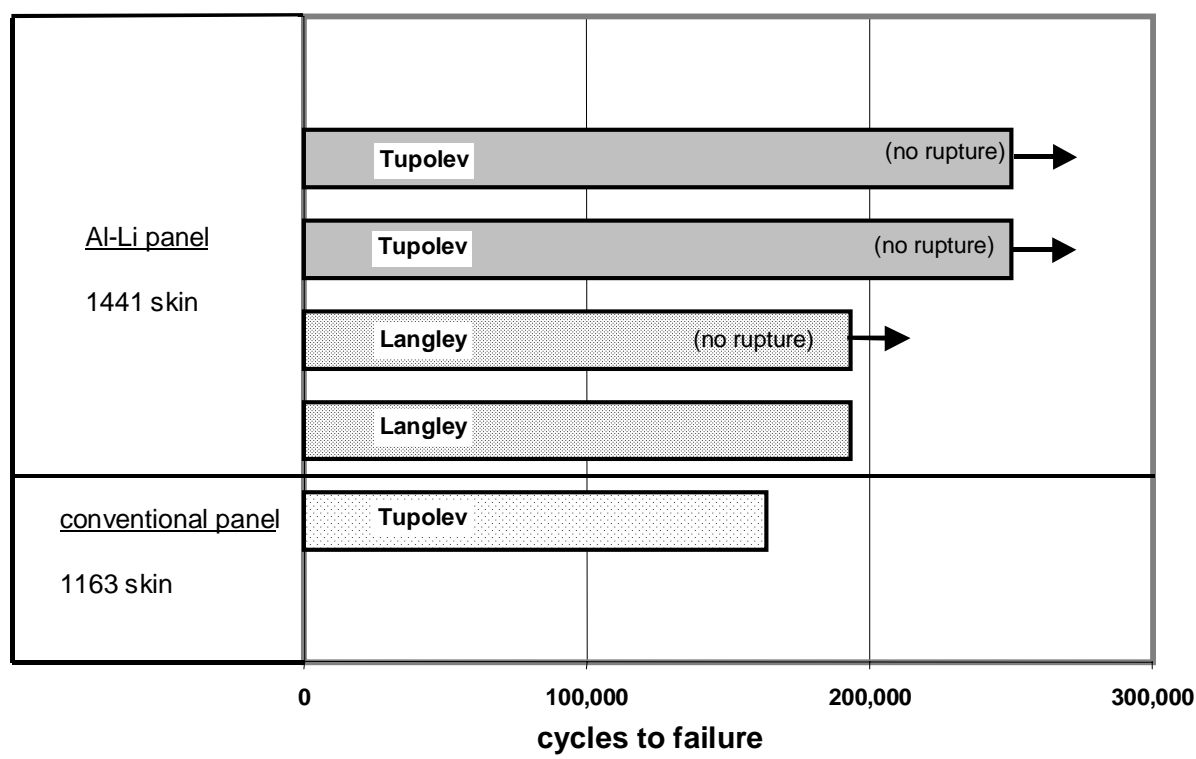

Figure 3: $\quad$ Tu-204 fuselage panel pressurization fatigue behavior [5]. 


\section{Conclusions}

The results of this study have shown that Russian 1441 Al-Li alloy mechanical properties are better than or similar to those for a conventional aluminum fuselage skin alloy. $1441 \mathrm{Al}-\mathrm{Li}$ sheet specimens exhibited strength, toughness, and tensile fatigue life similar to that for $1163 \mathrm{Al}$ $(2524 \mathrm{Al})$ sheet. In addition, the $1441 \mathrm{Al}-\mathrm{Li}$ had greater fatigue crack growth resistance than did 1163 Al. On a structural level, Tu-204 fuselage panels fabricated by Tupolev Design Bureau using 1441 Al-Li skin and ring frames and V95pchT2 Al (7475 Al) stiffeners had longer pressurization fatigue lives than did panels constructed from conventional aluminum alloys. The measured structural properties combined with the lower density of $1441 \mathrm{Al}-\mathrm{Li}$ indicate the potential to increase life of fuselage structure and decrease structural weight.

\section{References}

1. Altenpohl, Dietrich G.: Aluminum: Technology, Applications, and Environment, sixth edition. Aluminum Association, Inc., Washington, D.C. and the Minerals, Metals \& Materials Society, Warrendale, Pennsylvania, 1998, pp. 340-342.

2. Graham, R.H.; Rioja, R.J.; and Newman, J.M.: "Al-Li Alloy Development". AluminumLithium,Volume I, M. Peters and P.-J. Winkler, eds. Proceedings of the Sixth International Aluminum-Lithium Conference in Garmisch-Partenkirchen, FRG, 1991, pp. 15-24.

3. Fridlyander, J.N; Bratukhin, A.G.; and Davydov, V.G.: "Soviet Al-Li Alloys of Aerospace Application". Aluminum-Lithium,Volume I, M. Peters and P.-J. Winkler, eds. Proceedings of the Sixth International Aluminum-Lithium Conference in Garmisch-Partenkirchen, FRG, 1991, pp. 35-42.

4. $\quad$ Fridlyander, J.N; Bird, R.K.; Sadcov, V.V.; and Sandler, V.S.: "Al-Li (1441) High Technology and Service Life Alloy for Fuselage". Proceedings of the 5th International Symposium on Air Technologies for the 21st Century, August 8, 1999, Moscow, Russia.

5. Bird, R.K. and Dicus, D.L.: "Evaluation of Pressurization Fatigue Life of 1441 Al-Li Fuselage Panel". NASA Technical Memorandum TM-1999-209684, October 1999.

(R. K. Bird can be contacted at e-mail address r.k.bird@larc.nasa.gov) 